\title{
THE GREEN REVOLUTION: SOCIAL CHANGE THROUGH SOCIAL MEDIA
}

\author{
Veena Tripathi ${ }^{1 *}$ and Dhriti Bhattacharjee ${ }^{2}$ \\ ${ }^{1}$ Dept. of Management, D.D.U. Gorakhpur University, Gorakhpur, India \\ ${ }^{2}$ Shanti Business School, Ahmedabad, India \\ *Corresponding author's email: veena.tripathi06@gmail.com
}

\begin{abstract}
The advent of the internet changed the way we communicate forever. It became such a potent force that it was recommended as a nominee for Time Magazine's "Man of the Year." The world became euphoric about how this technology was changing the way we think. The changes were being brought about by people and that they were the change agents. It is required to understand the key concepts behind the emergence of social change through social media and their support in creating sustainability. This paper will report a study of five Indian social campaigns, right from their birth to the phase where they were no longer within the control of their parent organization but became a movement in their own rights. It is an exploratory study aimed at understanding the way social media works and how private organizations can also bring about a public change. The study will cover social networking sites like Facebook, Twitter and organizational blogs. The variables will be drawn from the corporate sustainability reports, social media venues, working papers and other research studies. These factors and variables can be correlated to sustainability through which the objective to analyse the impact of social change through social media can be achieved. With sustainability becoming a mandate for big companies in India, this study will help in understanding how social media can play a decisive role in their sustainability policies.
\end{abstract}

Key words: Sustainability; Social media; Social change; New media campaigns; Communication

\section{Introduction}

Internet and social media have changed the world communicates. The power of knowledge and information is no longer in the hands of a few. Now, everyone who has an internet connection can comment on anything that ranges from politics to office gossip. And among all these, social media has become a major agent for social change. Wikipedia defines social media as "a group of internetbased applications that build on the ideological and technological foundations of Web 2.0 and that allow the creation and exchange of user-generated content." It is a highly interactive medium of communication and individuals can share their opinions and thoughts with others through user-generated content.

This media has been instrumental in bringing in a lot of changes. With this new channel of communication, people have persuaded organizations to change many things. Even organizations have understood this and hence have increasingly started interacting with their customers. A new dimension in this interaction is about the social cause supported by for-profit companies.

The study selected five campaigns that have very different strategies to use the social media. The study is exploratory in nature and tries to understand the ways the private companies are changing their communication strategies because of the arrival of social media.

\section{Social Media and Corporate Social Responsibility}

The advent of Web 2.0 changed the way the world communicates forever. "Web 2.0 is a set of economic, social and technology trends that collectively form the basis for the next generation of the Internet, a more mature distinctive medium characterized by user participation, openness, and network effect"' (Musser and O'Reilly, 2005).

Social media has emerged as a new way of passing on information through web-based platforms like social networking sites, blogs, microblogging sites. These are open platforms where the receiver can comment, like or dislike the information. According to Fred Cavazza, "social media denotes a set of set of services allowing for developing social conversations and interaction over the internet or in a mobile situation."

According to Welhoff (2012) social media rests on five pillars. They are participation, where all users participate to give their opinions. The second is openness, that is, "social media is founded on the principles of collaboration and information exchange". The third is "conversation that is, 
fed by dialogue between the different users" and the fourth is "community, that is, social media allows for quickly building up communities of people sharing the same interests." And the fifth and the last one is "interconnection, that is, most social media outlets develop through interconnection by establishing links with other websites, resources or people."

Social media is a broad term that can be classified into online publication of opinions or information, content sharing sites, tools or sites allowing real time discussion, tools for microblogging or publishing and tools for social networking personal 'livecast' platform, virtual networking platforms and networked games sites (Cazzava, 2008).

With this evolution of technology, the human generations have also adapted themselves and their understanding of technology and each successive generation has used the various forms of social networks. The current generation is known as the internet or the multi-screen generation (Helme-Guizon and Ottmann, 2010). This generation is addicted to the social media and uses it in their day to day life.

In such a scenario, companies have also been forced to change the way they communicate with their customers. Today, the customer is no longer a passive receiver who is bombarded with information. Today, the customer believes that s/he now an "active co-creator" of corporate programmes (Curley \& Noormohammed, 2014). The customer chooses the company that matches his/her values and preferences.

On the other hand, companies are becoming socially conscious to improve their brand identity and also to contribute to a cause that goes with the core activity of the company. While the companies work on the ground, they use the social media to create awareness about the cause and in some cases, link their social media activity with their onground programme. All these form a part of the Corporate Social Responsibility (CSR) policy of the company wherein companies try to balance the profit requirements of the shareholders with the elements of social responsibility (Curley \& Noormohammed, 2014).

In India, it is still not mandatory for all companies to declare their CSR expenditure details and hence not much data is available. But in countries like USA, where such information is available, the CMO Survey of 2013, show that companies are spending 84 per cent of their budget on social media which is expected to grow in the next five years (Moorman, 2013). Though there is not much data available on Indian companies as the new Companies Act 2013 has become effective only from 1st April, 2014. There is still a lot of time pending for the companies to take a stock of their CSR initiatives and declare their figures.

\section{Social Media Marketing}

Social media marketing can be used to involve people in the following way, "ways to volunteer, to sign a petition, to spread the word, to really become advocates for the cause. It can help consumers track the impact of a company's involvement with a cause. It can add that human and emotional

component"

(http://www.cmo.com/branding/positive-effects-causerelated -marketing).

Involving the target audience through social media can be done in two major ways. According to Hall (2011), one would be create awareness and loyalty for the brand by making them the brand champions and to involve them by making them participate in a fun and creative way in some online activity and share that with their virtual friends.

Hence, marketing has now taken on a whole new dimension. Social Media Marketing is characterised by "User Generated Content" (Kaplan \& Haenlein, 2010) or "User Managed Content" (Ye et al., 2011) provided by "User Generated Media (Poynter \& Lawrence, 2008). The content is generated through continuous interactions and dialogues between the users who become collaborators (Erragcha \& Romdhane, 2014).

This new found collaborative effort then becomes bigger than individual efforts. People instantly access information that is available online and share them with their friends and groups almost instantaneously, discuss issues, like or dislike someone's opinion and also write or shoot one's reaction that will spread across that individual's virtual world like a wildfire.

\section{Social Media Marketing and CSR}

Now in this era of viral marketing, information can reach millions people in the shortest possible time using very less cost. So, it is a very effective medium to engage people not only to generate awareness but also to get them to do something for the cause. Social media marketing of causes has just evolved in India. Hence, very little literature is available on it. The study aims at addressing this gap by documenting five CSR campaigns undertaken by companies using the social media platform.

\section{Research Methodology}

The study uses content analysis which is described as the scientific study of content of communication. It is the content with reference to the meanings, contexts and intentions contained in messages. Holsti (1968) says that it is any technique for making inferences by systematically and objectively identifying specified characteristics of messages.

\section{Research Objectives}

- To understand how the social media is becoming a change agent for social change 
- To understand how companies are communicating their sustainability initiatives to the online world

- To understand how the target audience aligns itself with the companies' causes and spread it to their communities and friends

\section{Research Questions}

- How companies use the social media for their social campaigns?

- How target audience own the cause and share it with their communities and perform the actions sought by the companies?

\section{Data Collection and Analysis}

The five campaigns studied were selected randomly through internet search. Also, each campaign selected was unique. Each of them used social media differently from the others. This way, the study also brings out the flexibility of the social media where one can choose the way one wants to run a campaign.

Each campaign has been studied in detail and data has been collected from all possible sources.

\section{Scope and Limitation}

The study could have revealed many more aspects of different categories of companies focusing on sustainability initiatives. The paper only deals with a small sample size and the study is restricted to social media sites.

\section{The Five Campaigns}

\section{Garnier Power Light a Village}

The Garnier Power Light a Village is social initiative undertaken by Garnier Men in March, 2013. Close to 72 million Indians still live in darkness and 72,000 villages across India have no access to any light. The campaign was launched in collaboration with Chirag Rural Development Foundation (Project Chirag) with an aim to light up hundreds of rural households in India that are without any electricity. Here, consumers had an opportunity to help the organization electrify villages.

As a part of this initiative, every action made on the social media, would translate into actual energy donation on ground. The moment one clicks on the Facebook application, be it to comment, like or share, 10 watts of energy that gets contributed. Garnier will provide villagers each villager with one solar lamp with an in-built mobile charging unit, one solar tube light and one solar panel to charge their equipment. This equipment is charged by groups of physically challenged based in Maharashtra. In tropical country like India, where we have abundant sunlight, solar light units become an apt solution to our power problem.

This campaign was a part of the 'Men Who Matter' initiative of Garnier Men India which was initiated in 2012 and around 2 million men are a part of it on Facebook and Twitter. This campaign is more about serious social change and not about having mindless fun. It also breaks gender stereotypes by not talking about the usual bike and alcohol. The target audience of the campaign is men between the age of 15-35 and residing in Tier 1, 2, and 3 cities across India. The focus of the company was to urge these people to do tap their emotions to do something constructive for the society and become sensitive towards social issues.

This campaign "uses social currency, executed primarily across the digital platforms of Garnier Men to provide electricity to remote villages in India, the "PowerLIght A Village" campaign aimed at creating awareness among consumers to contribute through their pledges on social media"

(http://industry.shortyawards.com/nominee/6th_annual/AJ/ garnier-men-powerlight-a-village).

The campaign was launched by film actor John Abraham. After which Rajasthan Royals and Sunrisers Hyderabad from the Indian Premier League also joined this movement. Cricketers Rahul Dravid, Ajinkya Rahane, Shane Watson, Cameron White, Ishant Sharma and Dale Steyn rode PowerLight A Village bicycles in malls in Jaipur and Hyderabad to spread awareness about this campaign. This event was called 'Pedal to PowerLight' which was attended by young fans who got the opportunity to meet their favourite cricketers, receive grooming tips from Garnier Men and also come to know about the campaign.

The support from cricketers continued as Garnier organised a one-of-its kind Google+ Hangout that saw Rahul Dravid, Paddy Upton, Kumar Sangakarra, VVS Laxman and Krishnamachari Srikanth discuss cricket which also helped in spreading the word about the campaign.

The campaign then entered the second phase under which Garnier released a two-minute short digital film about a young boy, Om, who collects light so that his sister can study after sunset. The Table 1 shows the number of people who visited the various social media platforms.

Table 1: The number of people who visited the various social media platforms.

\begin{tabular}{|l|l|l|l|l|}
\hline \multicolumn{4}{|c|}{ Ingredients } & \multicolumn{1}{c|}{ Result } \\
\hline \multicolumn{4}{|c|}{ Independent Variable } & Dependent Variable \\
\hline FB page & FB share video & Tweets & Google handout live & Households \\
\hline $2,30,00,000$ & 23,651 & $18,94,769$ & $70,18,726$ & 800 \\
\hline
\end{tabular}




\section{Key Features}

- \#PowerLightAVillage trended on Twitter in India for 7 days in a row. While \#SolarLight and \#LightALife trended in India twice.

- Across the 2 phases of the campaign, close to 499,382 - half a million fans have joined the Garnier Men Facebook page.

- Increase in user engagement is close to $900 \%$.

- On an average 200,000 people are talking about the Garnier Men initiative on Facebook with a total reach $-23,000,000$

- Within 24 hours of its release, the digital film Om's Story received close to 10,690 views

- Cumulative views of the digital film across digital platforms - 2 Million

- Total tweets \& interactions for the Google+ Hangout - 30,263

The idea behind the campaign "Power Light a village" was to create awareness among society for their social actions. This social action would define as energy contribution via like, share \& comment. This campaign shows continued consumer shift to alternative media.

The idea "Power light a village" by Garnier is sparked by inspiration and brainstorming exercises. The idea got segregated specifically in three phases to run the campaign "The movement, the contribution and its impact" by designing three sections on Facebook.

In its first phase "the movement", this campaign got its name, where the name itself explains the idea behind the campaign. It got created on Facebook and Twitter, where the tag line was designed in such a way to make the consumer more clearly about the campaign.

In its second phase, "the contribution", the page displayed the virtual watts generated in real time through the energy meter by a single click. All single clicks as in like, share and comment was already set for predetermined unit of energy.

Consumer can contribute by either Facebook or Twitter login. Individual clicks on various messages for this campaign will generate different watts of energy. On one's contribution, a consumer can also check the total number of watts generated by one from various activities.

In its third phase "the impact", it shows the impact of campaign. Consumer can zoom on the map and able to locate the villages and browse the picture of every village that has been lit up.

The best part of Facebook app is consumers who contributed by using social media to support the campaign can chase their contribution via checking the villages which lit up from website.
Twitter page of campaign was also followed by $2.4 \mathrm{k}$ followers to contribute in the campaign via clicking on share, tweet and favourite. The Twitter campaign page was continuously uploaded with current status of the campaign and the followers could join the campaign with the hash tag \#power light a village to show their continuous support in the campaign.

\section{Stayfree Women for Change}

Stayfree Women for Change is an initiative undertaken by Johnson and Johnson "to support marginalized women and girls with equal opportunities by providing them improved health and hygiene facilities through health education, training and access to health and hygiene amenities, thus empowering them (http://www.stayfreewomenforchange.com/about-stayfreewomen-for-change)."

Stayfree has also partnered with two organizations named Samhita Social Ventures Private Limited and Nadathur Trust for a women's health programme named Support a Woman. The campaign is urges people to contribute Rs 330 on http://www.samhita.org/supportawoman which will include the following:

1. Two medical check-ups as well as counseling by a registered health care professional, in a span of six months.

2. Two hemoglobin estimation tests, in a span of six months.

3. A three-month course of iron and folic acid tablets.

4. Administrative and logistic costs to conduct the program.

In addition to this, Johnson and Johnson Ltd promised to provide six months' free supply of Stayfree sanitary napkins. Johnson and Johnson also agreed to bear the cost of operations and implementation of the programme. In order to get more information about this campaign, people can send the message "SUPPORT" to 56677.

This campaign spread the word through social media. The organization's website claims that the campaign has reached 10, 00, 000 girls.

Other than this, part of the proceeds from the sale of selected Stayfree packs shall be contributed to UNICEF for its health and hygiene programmes for adolescent girls in India.

This campaign uses all the channels of communication, both old and new ones. The contribution had to be made by an individual by paying but the awareness about it and the passing of the information happened both through social media and mobile phones. The vision of the programme is to "ensure every girl and woman has a healthy and hygienic life which we believe is every woman's right. (http://www.stayfreewomenforchange.com/about-stayfreewomen-for-change)." As a brand is a woman's brand, they 
believe that this campaign will enable it to bridge the gap between women with regards to health and hygiene. Their website says that this is step towards bringing equality between women and women. Only once this is done, will it be possible to close the gap between men and women.

As discussed earlier, Stayfree has partnered with Samhita Social Ventures Private Limited and Nadathur Trust. The latter was set up by N S Raghavan, Infosys co-founder. To implement the programme, Stayfree will bank on the network and expertise of the Samhita to make one of the largest women's health programme a huge success. The campaign urges people to contribute "to the support women programme and improve the life of a girl or woma, who in turn will change the lives of many girls and women around her (http://www.stayfreewomenforchange.com/aboutstayfree-women-for-change)."

Table 2 shows the number of girls who actually received sanitary napkins and the total number of people who accessed their Facebook, Twitter and YouTube posts.

Table 2: The number of girls who actually received sanitary napkins and the total number of people who accessed posts from social media

\begin{tabular}{|l|l|l|l|}
\hline \multicolumn{2}{|c|}{ Ingredients } & Result \\
\hline \multicolumn{2}{|c|}{ Independent Variable } & $\begin{array}{l}\text { Dependent } \\
\text { Variable }\end{array}$ \\
\hline \multirow{2}{|c|}{ FB page } & $\begin{array}{l}\text { You } \\
\text { Tube } \\
\text { video }\end{array}$ & Tweets & $\begin{array}{l}\text { Girls Received } \\
\text { Sanitary napkin }\end{array}$ \\
\hline $4,51,949$ & $4,83,662$ & 4831 & $10,00,000$ \\
\hline
\end{tabular}

The idea to start the campaign Stayfree "women for change" is to support women health and education, as the name suggest. The concept to run this movement is to establish Stayfree as a brand which 'believes in change'.

The campaign was segregated into four phases: planning, application, medication \& result.

In its first phase, the idea to run the campaign was planned in the form of creating separate website for this forum and by creating page on Facebook. The campaign specifically mentioned women, to make the consumer clear about the target segment. Under the movement tagline, the formation was very clear, to support women for good changes in the form of health, education and support to stand on their own feet.

In its second phase, 'application', a heart-touching video was launched which was highlighting a young girl carefree childhood days, where her shackled life got transitioned to woman. The lyrics and the video designed to such a way to make consumer very clear about the chains of a women which society treats as her ornament. The same video was also posted on Facebook. Consumer had to like the page and message 'Support 'at 56677. More than four lakh consumers liked it and more than 4000 consumers retweeted on Facebook and Twitter, respectively.

In its third phase, medication, the campaign, 'Stayfree women a change' started working actually on its idea in the form of education and health checkups, distribution of sanitary napkins as per their policy of contribution which was mentioned on the website, Facebook app and twitter. Consumers could also call on the number and can chase their contribution in the campaign.

In the last phase result, campaign showed its success as more than ten lakh girls who are associated with the Stayfree (mentioned above).

\section{Vodafone Selfie4school}

Vodafone's Selfie4school is another social change campaign undertaken by a for-profit organization as an effort to change the way we live. Vodafone is a multinational mobile telephone service provider and has enough funds at its disposal to work for girls education and create awareness about the ill-effects of early marriage. However, it took the help of social media. Vodafone started a campaign wherein one had to click a selfie and then upload it on social networking sites like Facebook and Twitter with the hashtag \#selfie4school. For each selfie uploaded, Vodafone Foundation promised to send 10 girls to school. The campaign was launched with a target of 25,000 girls but soon the campaign became so popular that it surpassed its target.

Like in the case of the previous two campaigns, Vodafone also partnered with a NGO. The organization with whom they partnered is Breakthrough, a human rights organization. The logic behind the campaign was that a selfie which is often viewed as an activity promoting narcissism, is a luxury for many girls who do not have access to technology. Hence, this otherwise "frivolous" activity was transformed into a tool for bringing social change.

The campaign has an exclusive website which one log on to via Facebook, Google Plus or Twitter account. There is also a selfie wall where one can see the selfies of all the people who have participated. After uploading the selfie, one can also share it with one's friends and contacts on the social networking sites. There is also a video on the Youtube channel of breakthrough which tells the story of a young girl who because of school has been able to delay her marriage, complete her education and has been able to support her family.

The campaign was launched on 5th September, 2014, and ended on 9th October, 2014. By the time it got over, it had reached 47,410 girls. 
The campaign has an exclusive website which one log on to via Facebook, Google Plus or Twitter account. There is also a selfie wall where one can see the selfies of all the people who have participated. After uploading the selfie, one can also share it with one's friends and contacts on the social networking sites. There is also a video on the Youtube channel of breakthrough which tells the story of a young girl who because of education has been able to delay her marriage, complete her education and has been able to support her family.

The idea to start this campaign is to give education to a child who won't be able to go school because of financial issues with the help of contribution of consumer. Vodafone followed three stages in running the campaign. These stages were idea generation, application and formation.

First stage of idea generation focused on formation of tagline and plan to visualize the target. The goal was education of 25000 girls within one year and the consumer as a contributor had to send their selfies.

In its second stage, application, Vodafone outsourced Ignitee Digital Agency to create a dedicated website which was run by social logins. Consumers could contribute via Facebook, Google plus, Twitter and by uploading their videos on Youtube.

In the last stage, formation, the campaign received huge success. The campaign was launched on 5th September, 2014, and ended on 9th October, 2014. By the time it completed, it had reached 47,410 girls. On Twitter, the campaign was successful in creating awareness and raising the conversation by using the hashtag \#selfiesforschool. People also gave their views on child marriage, education and health issues on Twitter. Many celebrities shared their selfies and supported the campaign. Indicator as a consumer to share the selfie was they can also share the wall on their profile link.

\section{Sab Miller Respect the Road}

Sab Miller India is the second largest beer company of India and owns ten breweries with popular brands. Sab Miller launched a Respect the Road campaign that won the Best Social Media Campaign award of FICCI International Sustainability Awards, 2013. The campaign was launched in 2011 and is still on. It urges people to behave responsibly after drinking alcohol by either calling a cab, asking a driver or a friend to drop them home. It used a multi-pronged strategy for the campaign and used social media to spread the message. It is liked by 32,127 people on Facebook. Other than social media, the campaign was promoted through live media screens across 50 outlets in NCR, branding at selected petrol pumps, street play competition at leading business schools and participation at conferences and seminars. It has also partnered with Home Safe, Delhi
NCR's first chauffer service, taxi service providers Mega Cabs and radio station Radio City 91.1 FM.

Sab Miller uses its Facebook page to hold quizzes on road safety to increase awareness about traffic rules. In December, 2013, during the New Year's eve, Sab Miller had set up a liquor booth outside Ardor, a popular joint at Connaught Place, New Delhi. One could go to the booth and get oneself clicked with the campaign tagline at the background and upload the picture on a social networking site instantly.

Sab Miller also uploaded videos on You Tube but they did not become popular. For example, the video "Respect the Road - Public Service CSR campaign of SabMiller" was viewed by only 39 people. Its Twitter page is also not hugely successful with only 4,786 tweets as shown in Table 3.

Table 3: Data showing media hits for "Respect the Road Public Service CSR campaign of SabMiller".

\begin{tabular}{|l|l|l|}
\hline \multicolumn{3}{|c|}{ Ingredients } \\
\hline \multicolumn{3}{|c|}{ Independent Variable } \\
\hline FB page & You Tube video & Tweets \\
\hline 32,127 & 39 & 4,786 \\
\hline
\end{tabular}

\section{Google India's Reach the Sky Campaign}

Google India launched an initiative Helping Women Get Online (HWGO) to empower women to use the internet. Data shows that more men than women access internet than men, only 30 per cent women access internet. Google says that studies prove that if women used internet then it would have a very positive impact on their lives and on the society at large.

Through this campaign, Google aims at introducing 50 million additional women to the digital world by the end of 2014. Google has collaborated with Unilever, Future Group and Axis Bank for this campaign so that it gets more access points to reach out to more number of women. They have partnered with Johnson \& Johnson, Indiatimes, Healthkart, Babyoye and such organizations to create content that would provide relevant information to the women.

The campaign includes the following includes the website www.hwgo.com, an internet toll free helpline and on-theground activities. According to Google, the first phase of the campaign has been "hugely successful" as the number of women accessing internet has gone up by 35 per cent as compared to men (31 per cent) (http://indianexpress.com/article/india/india-others/googleindia-launches-new-campaign-with-farhan-akhtar-to-helpwomen-get-online/).

\section{Conclusion}

The potential of social media is yet to be exploited to its full potential in India. But the beginning has been made. The 
five initiatives explained above have started using social media to further their business interests. And they have met with considerable success. Thousands of people have associated themselves directly with their causes and indirectly with their brands. One can do further research to find out the opinions and perceptions of the consumers and social media users about these initiatives. But in the meanwhile, one can safely assume that social media is here to stay and is an effective medium to bring about change in our society.

\section{References}

Cazzava F (2008) Social Media Landscape.

Constantinides E (2014) Foundation of Social Media Marketing. Procedia Social and Behavioral Science 148: 40-57.

Curley CB and Noormohammed NA (2014), Social Media Marketing Effects on Corporate Social Responsibility. Journal of Business \& Economics Research 12(1): 61-66.

Erragcha N (2014) Social Network as Marketing Tools, Journal of Internet Banking and Commerce, 1-12.

Hall L (2010) Tying together social media and corporate social responsibility, retrieved

from http://www.convinceandconvert.com/pr-20/tyingtogether-social-media-and-corporate-socialresponsibility/

Helme-Guizon A and Ottmann M (2010) Generation Y et marketing, Evolution ou revolution? Decisions Marketing, 83-86.

Kaplan AM and Haenlein M (2010) Users of the World, Unite! The challenges and opportunities of Social Media. Business Horizons 59-68.

Moorman C (2013) Do marketers know what they want from social media? Retrieved from http://cmosurvey.org/blog/do-marketers-know-what-theywant-from-social-media/

Musser J and O'Reilly T (2005) Web 2.0 Principles and Best Practices, O’Reilly Media,ISBN - 10, 0-596-52769-1

Poynter R and Lawrence G (2008) Insight 2.0: Nouveaux Medias, nouvelles regles, nouvelle vision approfondie. Revue Francaise du Marketing, 25-38.

Vagdevi HS and Shantharaju S (2014) The intermix of social media in propelling the social change. The Journal of Applied Research 101-102. 